\title{
EFEKTIVITAS KONSELING KELOMPOK TERHADAP MOTIVASI BERHENTI MEMAKAI NARKO'TIKA, PSIKOTROPIKA, DAN ZAT ADIKTIF
}

\author{
Yudi Guntara, Ridwan Saepul Rohmat \\ Bimbingan Penyuluhan Islam STID Sirnarasa \\ iwanvanjava70@gmail.com
}

\begin{abstract}
ABSTRAK
Penelitian ini dilatar belakangi oleh adanya komunitas Pendidikan NAPZA Tasikmalaya (Pentas) di Ciputri, Kecamatan Singaparna, Kabupaten Tasikmalaya, Jawa Baratyang terdiri dari anggota rehabilitasi rawat jalan dan korban Narkotikea, Psikotropika, dan Zat Adiktif (NAPZA) yang sudah pulih dengan atas kesadaran dan kemauan tinggi untuk terbindar kembali dari penggunaan NAPZA. Metode penelitian menggunakan kombinasi antara kuantitatif dan kualitatif yang berlokasi di ciputri, singaparna tasikmalaya. Hasil dari penelitian ini terdapat peningkatan motivasi anggota komunitas pendidik.an NAPZA untuk berhenti dalam menyalah gunakan $N A P Z A$.
\end{abstract}

Kata Kunci : Konseling, motivasi, NAPZA

\section{ABSTRACT}

This research was motivated by the existence of the Tasikmalaya Drug Education (Pentas) community in Ciputri, Singaparna District, Tasikmalaya Regency, West Java, which consists of outpatient rehabilitation members and victims of Narcotics, Psychotropics, and Addictive Substances (NAPZA) who have recovered with awareness and willingness to avoid returning from drug use. The research method uses a combination of quantitative and qualitative, located in Ciputri, Singapore, Tasikmalaya. The results of this study indicate an increase in the motivation of members of the drug education community to stop abusing drugs.

Keywords: counseling, motivation, NAPZA 


\section{PENDAHULUAN}

Mengutip dari Badan Narkotika NasionaL mengungkapkan bahwa Indonesia dikenal produsen ekstasi nomor satu di dunia. Sebagai pengedar, Indonesia dikenal sebagai pengedar ganja terbesar di dunia. Hal tersebut memungkinkan karena ganja dari Indonesia merupakan mariyuana dengan kualitas nomor satu di dunia.

Pemerintah Indonesia, melalui Menteri Keuangan Sri Mulyani, tidak memungkiri bahwa Indonesia saat ini mendapatkan 'banjir narkoba yang tiap hari terus meningkat'. Sri Mulyani mengutarakan hal itu saat jumpa pers bersama Kepala Polisi Republik Indonesia Jendral Tito Karnavian di pelabuhan Sekupang, Batam, Kepulauan Riau, Jumat, 23 Februaru 2018.

Untuk itu pemerintah berusaha memberantas NAPZA serta memberikan edukasi kepada masyarakat mengenai bahaya bArang tersebut jika disalahgunakan. Menurut Deputi bidang pencegahan Badan Narkotika Nasional (BNN) Ali Djohardi sebagaimana yang dikutip oleh situs BBC (https://www.bbc.com/indonesia /indonesia -43198966, akses tanggal 01 Oktober 2018 pukul 20.10 WIB) menyebut 80 persen masyarakat Indonesia mengetahui jenis dan bahaya narkoba. Namun anehnya tingkat penyalahgunaan narkoba di Indonesia masih tinggi. Hasil penelitian BNN yang bekerjasama dengan Pusat Penelitian Kesehatan Universitas Indonesia (UI) Tahun 2011 tentang survei nasional perkembangan penyalahgunaan narkotika di Indonesia sebagaimana dalam situsnya BNN (http://diklat.bnn.go.id/?p=4400, akses tanggal 16 Februari 2019 pukul 13.09 WIB) diketahui bahwa angka prevalensi penyalahguna narkotika di Indonesia telah mencapai 2,23\% atau sekitar 4,2 juta orang dari total populasi penduduk (berusia 10 - 59 tahun).

Kepala Badan BNN, Anang Iskandar dalam seminar "Survei Nasional Perkembangan Penyalahgunaan Narkoba di 17 Provinsi Tahun 2014" sebagimana yang dikutip oleh situs Berita Satu (https://www.beritasatu.com / kesra/226075bnn-jawa-barat-pengguna-narkoba-terbanyak.html, akses tanggal 03 Maret 2019 pukul 13.11 WIB) mengatakan bahwa, "Berdasarkan data Badan Narkotika Nasional (BNN), pengguna narkoba di Indonesia mencapai 4,2 juta jiwa dan terus meningkat tiap tahunnya. Rata-rata berjenis kelamin laki-laki dan berpendidikan tinggi dengan rata-rata usia 26 tahun."

Jika ditinjau dari pengguna narkoba berdasarkan provinsi, BNN menyatakan, Jawa Barat sebagai provinsi yang mendominasi jumlah pengguna narkoba terbanyak di Indonesia sepanjang tahun 2014. Dengan jumlah sekitar 700.000 jiwa.

Menurut kepala BNN Brigadir Jendral Polisi Sufyan Syarif sebagaimana yang dikutip Tribun News (https://jabar.tribunnews .com/2019/07/26/penyalagunaan-narkoba-di-jabar-meningkat-tasikmalaya-jadi 
wilayah-transit-perdagangan-narkoba, diakses tanggal 03 Agustus 2019 pukul 11.38 WIB) menyebut bahwa Tasikmalaya, Jawa Barat merupakan wilayah yang rawan penyalahgunaan NAPZA. Hal itu dikarenakan Tasikmalaya adalah wilayah jalur transit perdagangan di Jawa bagian Selatan.

Untuk warga negara Indonesia yang sudah memakai Narkotika, Psikotropika, Zat Adiktif (NAPZA), pemerintah menghimbau kepada masyarakat untuk melaporkan hal itu ke puskesmas terdekat untuk dilakukan penilaian (assesment) terlebih dahulu sebelum diberikan pelayanan rehabilitasi yang berupa rawat jalan atau rawat inap.

Selain itu ada beberapa komunitas yang memang tergerak hatinya untuk membantu sesama pecandu narkoba untuk bisa pulih dari kecanduan narkoba. Salah satunya adalah komunitas Pendidikan NAPZA Tasikmalaya (Pentas) di Ciputri, Kecamatan Singaparna, Kabupaten Tasikmalaya, Jawa Barat.

Komunitas tersebut merupakan sebuah komunitas yang terdiri dari anggota rawat jalan dan korban Narkotika, Psikotropika, dan Zat Adiktif (NAPZA) yang sudah pulih. Komunitas ini ada atas dasar kesadaran dan kemauan tinggi untuk terhindar kembali dari penggunaan NAPZA yang bekerjasama dengan Institusi Penerima Wajib Lapor (IPWL) Puskesmas setempat.

Meskipun nama komunitasnya adalah komunitas Pendidikan NAPZA Tasikmalaya (Pentas). Akan tetapi komunitas ini dikhususkan untuk korban NAPZA yang berada di wilayah Singaparna saja.

Hal ini menuntut perlunya konseling kelompok agar korban penyalahgunaan Narkotika, Psikotropika, dan Zat Adiktif (NAPZA) tidak merasa dirinya sendirian. Serta mereka akan segera menyadari bahwa mereka tidak hanya mempunyai kesamaan yang sama dalam hal pemikiran dan perasaan.

Menurut penjelasan Guntur (29 Januari 2019) selaku peer counselor, komunitas Pendidikan NAPZA Tasikmalaya (Pentas) di Ciputri, Kecamatan Singaparna, Kabupaten Tasikmalaya, Jawa Barat ada sekitar 29 anggota yang terdiri dari 5 orang korban Narkotika, Psikotropika, dan Zat Adiktif (NAPZA) yang sudah pulih dan 24 orang yang masih rehabilitasi rawat jalan. Berdasarkan latar belakang di atas. Maka peneliti tertarik untuk meneliti Komunitas Pentas di Sigaparna, Kabupaten Tasikmalaya, Jawa Barat. Efektivitas konseling kelompok terhadap motivasi berhenti memakai Narkotika, Psikotropika, Zat Adiktif (NAPZA).

Terdapat beberapa rumusan pertanyaan diantaranya: (a) Bagaimana proses konseling kelompok di komunitas Pendidikan NAPZA Tasikmalaya (Pentas) di Ciputri, Kecamatan Singaparna, Kabupaten Tasikmalaya, Jawa Barat? (b) Bagaimana efektivitas konseling kelompok terhadap motivasi berhenti memakai Narkotika, Psikotropika, Zat Adiktif (NAPZA)?. (c) Apa faktor pendukung dan penghambat proses konseling kelompok di komunitas 
Pendidikan NAPZA Tasikmalaya (Pentas) di Ciputri, Kecamatan Singaparna, Kabupaten Tasikmalaya, Jawa Barat?.

\section{LANDASAN TEORITIS}

Enjang dan Aliyudin (2001: 142) mengemukakan bahwa salah satu bentuk kegiatan dalam dakwah adalah irsyad. Secara bahasa, irsyad adalah bimbingan. Sedangkan irsyad secara istilah adalah proses penyampaian dan internalisasi ajaran Islam melalui kegiatan bimbingan, penyuluhan, dan psikotrerapi islam dengan sasaran individu atau kelompok.

Sedangkan menurut Burks dan Sefflre sebagaimana yang dikutip oleh Sulistyarini dan Jauhar (2014: 31) mengemukakan konseling merupakan hubungan profesional antara konselor terlatih dengan konseli. Hal ini sejalan dengan pengertian menurut Jones yang dikutip oleh Sulistyarini dan Jauhar (2014: 31) menyatakan bahwa konseling merupakan suatu hubungan profesional antara seorang konselor yang terlatih dengan klien. Hubungan ini biasanya bersifat individual atau seorang-seorang, meskipun kadang-kadang melibatkan lebih dari dua orang dan dirancang untuk membantu klien memahami dan memperjelas pandangan terhadap ruang lingkup hidupnya, sehingga dapat membuat pilihan yang bermakna bagi dirinya.

Konseling bisa diarahkan kepada sekelompok individu (Sulistyarini dan Jauhar, 2014: 31). Menurut Rasimin dan Hamdi (2018: 4) kelompok merupakan media penghubung antar individu yang tergabung didalamnya, yang memungkinkan berpartisipasi secara aktif dalam berbagi pengalaman, pengembangan wawasan, sikap dan keterampilan, pencegahan munculnya masalah, atau pengembangan pribadi anggota.

Rasimin dan Hamdi (2018: 7) menjelaskan bahwa konseling kelompok bersifat pencegahan atau preventif, dalam arti bahwa individu yang dibantu mempunyai kemampuan normal atau berfungsi secara wajar dimasyarakat, tetapi memiliki beberapa kelemahan dalam kehidupan sehingga mengganggu kelancaran komunikasi dengan orang lain. Sedangkan, konseling kelompok bersifat penyembuhan dalam pengertian membantu individu untuk dapat keluar dari persoalan yang dialami dengan memberikan kesempatan, dorongan, dan juga pengarahan agar bisa selaras dengan lingkungannya.

tujuan layanan konseling kelompok mengacu pada mengapa kelompok mengadakan pertemuan dan apa tujuan serta sasaran yang hendak dicapai. Menurut Brown yang dikutip oleh Kurnanto (2014: 10) mengatakan bahwa ketika pemimpin sepenuhnya memahami tujuan kelompok, lebih mudah baginya untuk memutusakan hal-hal seperti ukuran, keanggotaan, panjang sesi, dan jumlah sesi dalam kelompok. 
Menurut Uno (2013: 3) motivasi berasal dan kata "movere" yang berarti mendorong atau menggerakkan. Istilah motivasi berasal dari kata motif yang dapat diartikan sebagai kekuatan yang terdapat dalam diri individu. Menurut Mc Donald Sebagaimana yang dikutip oleh Sudirman (1996: 73) menyatakan bahwa motivasi adalah perubahan energi dalam diri seseorang yang ditandai dengan munculnya "felling" dan didahului dengan tanggapan terhadap adanya tujuan.

Muhaimin yang dikutip oleh Hamalik (2001: 158) mengartikan motivasi sebagai tenaga pendorong atau penarik yang menyebabkan adanya tingkah laku ke arah suatu tujuan tertentu. Sedangkan menurut Sumardi Suyabrata yang dikutip oleh Djaali (2009: 101) mengemukakan bahwa motivasi adalah keadaan yang terdapat dalam diri seseorang yang mendorongnya untuk melakukan aktivitas tertentu guna pencapaian suatu tujuan.

Menurut Makmun (2007: 37) mengatakan bahwa meskipun para ahli mendefinisikannya dengan cara dan gaya yang berbeda, namun esensinya menuju kepada maksud yang sama, ialah bahwa motivasi itu merupakan suatu kekuatan (power) atau tenaga (force) atau daya (energy) atau suatu keadaan yang kompleks (a complex state) dan kesiapsediaan (preparatory set) dalam diri individu (organisme) untuk bergerak (to move, motion, motive) ke arah tujuan tertentu, baik disadari maupun tidak disadari.

Penelitian ini dilaksanakan di komunitas Pendidikan NAPZA Tasikmalaya (Pentas) di Ciputri, Kecamatan Singaparna, Kabupaten Tasikmalaya, Jawa Barat pada bulan Juli - Agustus 2019. Sasaran dalam penelitian ini adalah anggota komunitas Pentas. Pemilihan lokasi berdasarkan observasi pada bulan Januari 2019, dimana ditemukan masalah yang perlu diteliti. populasinya 29 Anggota aktif komunitas Pendidikan NAPZA Tasikmalaya (Pentas) di Ciputri, Kecamatan Singaparna, Kabupaten Tasikmalaya, Jawa Barat yang terdiri dari 5 orang korban Narkotika, Psikotropika, dan Zat Adiktif (NAPZA) yang sudah pulih dan 24 orang yang masih dalam tahap rehabilitasi rawat jalan.

Pada penelitian ini populasi kurang dari 100 orang maka diambil semua untuk dijadikan sampel. Dalam penelitian populasinya 29 Anggota komunitas Pendidikan NAPZA Tasikmalaya (Pentas) di Ciputri, Kecamatan Singaparna, Kabupaten Tasikmalaya, Jawa Barat yang terdiri dari 5 orang korban Narkotika, Psikotropika, dan Zat Adiktif (NAPZA) yang sudah pulih dan 24 orang yang masih dalam tahap rehabilitasi rawat jalan.

\section{HASIL DAN PEMBAHASAN}

Komunitas Pendidikan Narkotika, Psikotropika, dan Zat Adiktif (NAPZA) Tasikmalaya (Pentas) di Ciputri, Kecamatan Singaparna, Kabupaten Tasikmalaya, Jawa Barat mempunyai 29 anggota yang terdiri dari 5 orang korban Narkotika, Psikotropika, dan Zat Adiktif (NAPZA) yang sudah pulih dan 24 
orang yang masih rehabilitasi rawat jalan. Semua anggota yang tergabung sebagai komunitas Pendidikan NAPZA Tasikmalaya (Pentas) di Ciputri, Kecamatan Singaparna, Kabupaten Tasikmalaya, Jawa Barat adalah orang Singaparna yang menjadi korban Narkotika, Psikotropika, dan Zat Adiktif (NAPZA). komunitas Pendidikan NAPZA Tasikmalaya (Pentas) di Ciputri, Kecamatan Singaparna, Kabupaten Tasikmalaya, Jawa Barat dibantu oleh 2 peer counselor yaitu Guntur Hermawan dan Zezen Alberto.

\section{Proses Konseling Kelompok di Komunitas Pendidikan NAPZA Tasikmalaya (Pentas) di Ciputri, Kecamatan Singaparna, Kabupaten Tasikmalaya, Jawa Barat.}

Dalam pembahasan ini peneliti melakukan wawancara dengan peer counselor yaitu Guntur Hermawan dan Zezen Alberto serta wawanacara dengan beberapa anggota komunitas untuk mengetahui proses konseling kelompok yang didalamnya terdapat dinamika kelompok, proses kelompok, dan dorongan terapeutik.

Seperti yang telah dikemukakan pada bab sebelumnya, bahwa dalam literatur konseling kelompok ada tiga hal yang hampir selalu dibicarakan, yaitu dinamika kelompok, proses kelompok, dan dorongan terapeutik.

Dinamika kelompok biasanya mengacu kepada sikap dan interaksi antar sesama anggota kelompok dan antara anggota kelompok dengan pemimpin kelompok. Proses kelompok mengacu pada tahapan kegiatan dan perkembangan perubahan yang terjadi dalam kelompok. Dorongan terapeutik merupakan faktorfaktor yang mempengaruhi dinamika kelompok dan proses kelompok. Ketiga hal tersebut harus ada agar proses konseling kelompok dapat berjalan dengan sesuai harapan.

Pada Bab sebelumnya dijelaskan bahwa proses terbentuknya kelompok terbagi menjadi 4 tahap yaitu : tahap pembentukan, tahap peralihan, tahap kegiatan, dan tahap pengakhiran. Hal ini sesuai dengan yang ada di komunitas Pendidikan NAPZA Tasikmalaya (Pentas) di Ciputri, Kecamatan Singaparna, Kabupaten Tasikmalaya, Jawa Barat. Sebagaimana yang disampaikan dalam hasil wawancara peneliti dengan Hermawan (05 Juli 2019) sebagai berikut :

"tahapan proses pembentukan kelompok di komunitas terbagi jadi 4 tahap kang. Tahap pembentukan awal, tahap peralihan untuk menunjang tahap satu dan tiga, tahap kegiatan, dan tahap pengakhiran atau evaluasi kang."

Adapun tahap proses kelompok di komunitas Pendidikan NAPZA Tasikmalaya (Pentas) di Ciputri, Kecamatan Singaparna, Kabupaten Tasikmalaya, Jawa Barat sebagai berikut: Pertama tahap pembentukan bagaimana seorang pemimpin dapat berpikir dengan baik tentang jenis kelompok yang diinginkan, serta dapat mempersiapkan diri secara psikologis dalam menciptakan situasi dan 
kondisi konseling yang sesuai. Pada tahap ini Hermawan (05 Juli 2019) mengungkapkan bahwa:

"Sebelum memulai konseling kita selalu pastiin dulu tempatnya dimana, mau berapa lama, dan siapa aja yang mau datang. Biar kita sebagai peer counselor mereka yang mendampingi mereka tahu gimana proseduryang pas buat kelompok. itu. Kalau dari konseling kelompok secara umumnya kita langsung menyinggung sedikit babwa di konseling kelompok ini kita akan membantu permasalahan anggota konseling dan saling memberikan motivasi, harapan, manpun saran satu sama lainnya. Biasanya kita menentukan apa yang ingin dibahas misalnya apa mau langsung ke masalah pribadi yang ingin curbat atau bal yang umum dabulu misal berkaitan dengan pemahaman tentang narkoba, pertolongan pertama dan lainnya. Biasanya untuk. sesi pertama kita bahas dari bal-bal umum dan mulai merambah kepermasalahan pribadi serta dimulainya curbat satu sama lain dan saling memberikan saran. Nab kondisi orang yang mengikuti juga selalu kita pantau. Kita mengamati mana orang yang dominan mana orang yang jarang bicara saat konseling."

Kedua tahap peralihan merupakan jembatan antara tahap pertama dengan tahap ketiga. Tujuan dari tahapan peralihan adalah keterbebaskannya anggota dari perasaan atau sikap enggan, ragu, malu, atau saling tidak percaya untuk memasuki tahap berikutnya, makin bagusnya suasana kelompok dan kebersamaan, makin bagus juga minat untuk ikut serta dalam kegiatan kelompok.

Dalam sesi peralihan di komunitas Pendidikan NAPZA Tasikmalaya (Pentas) di Ciputri, Kecamatan Singaparna, Kabupaten Tasikmalaya, Jawa Barat biasanya dilakukan jika konseling kelompok diadakan untuk sesi pertama kalinya atau jika ada anggota baru untuk menghilangkan rasa sikap enggan, ragu, malu, atau saling tidak percaya. Sebagaimana hal yang diungkapkan Hermawan (05 Juli 2019) selaku peer counselor sebagai berikut :

"Kalau untuk tahap peraliban biasanya kita pakai pas pertama kali melakukan sesi konseling atau ada anggota yang masih malu-malu. Pada tahap ini kita lebih lebib ke penguatan di tahap pertama kang misal kaya udah akrab atau belum terus udah mulai saling menerima dan percaya apa belum. Cuma ya ... fleksibel kang tergantung udah berapa kali sesi. Kalau sudah beberapa kali sesi konseling sib kita biasanya langsung ke pembahasan masalah. Karena suasananya udah terbentuk."

Dari ungkapan diatas bahwasannya tahap peralihan ini bersifat fleksibel. Jadi kelompok tidak selalu harus memasuki tahap peralihan karena tahap peralihan hanya digunakan pada saat sesi pertama kali dalam konseling kelompok atau ada anggota baru yang masih malu serta lebih ke penguatan dorongan terapeutik pada tahap pertama yaitu keakraban, dan kepercayaan serta penerimaan.

Ketiga Tahap Pelaksanaan Kegiatan bertujuan membahas suatu masalah atau topik yang relevan dengan kehidupan anggota secara mendalam dan tuntas. 
Dalam tahap ini peer counselor mengumumkan suatu masalah atau topik tanya jawab antara anggota dan peer counselor tentang hal-hal belum jelas yang menyangkut masalah atau topik tersebut secara tuntas dan mendalam. Tahap ini juga disebut dengan tahap inti dalam proses kelompok. berkaitan hal ini Sebagaimana hasil wawancara peneliti dengan Hermawan (05 Juli 2019) mengungkapkan bahwa;

"Pada tahap ini mulai membahas masalah secara lebih mendalam antar satu anggota dengan anggota lainnya. Saya hanya sedikit menambahkan jika perlu dalam tahap ini. Karena anggota lainnya juga ikut serta memberikan saran dan motivasi juga pada teman yang mempunyai masalah."

Berdasarkan ungkapan diatas menunjukan bahwa pada tahap pelaksanaan kegiatan kelompok berfokus pada masalah yang dihadapi dan membahasnya secara bersama-sama secara medalam dan tuntas. Peer counselor juga tidak mengganggu jalannya dinamika kelompok yang diperankan oleh anggota kelompok dengan menghindari pola interaksi dua arah antara peer counselor dengan anggota.

Mengenai peran anggota kelompok peneliti mewawancarai Alberto (17 Juli 2019) selaku peer counselor di komunitas Pendidikan NAPZA Tasikmalaya (Pentas) di Ciputri, Kecamatan Singaparna, Kabupaten Tasikmalaya, Jawa Barat memberikan pendapat sebagai berikut:

"seorang anggota harus berperan dalam konseling kelompok agar konseling itu bisa berjalan dengan baik. Karena pada konseling kelompok peran anggota seperti akrab satu sama lain, saling bantu, sadar konseling itu penting, ngasih kesempatan ke yang lain buat mengungkapkan masalahnya, membantu buat aturan, dan lainnya yang menunjang konseling itu dari anggota itu. Sangat penting itu kang terhadap proses konseling kelompok."

Dinamika konseling kelompok sangat penting terhadap proses konseling kelompok karena secara khusus dinamika kelompok dapat dimanfaatkan untuk pemecahan masalah pribadi anggota kelompok, yaitu apabila interaksi dalam kelompok itu difokuskan pada pemecahan masalah pribadi yang dimaksudkan.

Empat tahap penutupan ada dua cara menutup konseling yaitu, menutup sesi (closing phase) dan menutup seluruh rangkaian sesi (closing stage). Menutup sesi (closing phase) adalah periode sesi ketika pemimpin menutup seluruh kegiatan sesi. Menutup seluruh rangkaian sesi (closing stage) mungkin sesi terakhir dari kelompok atau beberapa sesi terakhir.

Pada komunitas Pentas konseling kelompok hanya menutup sesi (closing phase) dan tidak menutup seluruh rangkaian sesi (closing stage). Sesuai dengan Hasil wawancara peneliti dengan Hermawan (05 Juli 2019) sebagai berikut :

"Di komunitas Pentas setelah tahap konseling kita lakukan evaluasi dan menutup sesi namun kami tidak menutup keseluruhan rangkaian sesi. Karena 
pada dasarnya korban bisa kembali memakai narkoba jika tidak ada dukungan secara psikologisnya tidak terpenuhi. Maka dari itu kita tidak menutup rangkaian konseling secara keseluruhan. Dan juga pada setiap sesi akhir kita selalu menguatkan komitmen mereka dan masih ada jalan selain pakai narkoba."

Berdasarkan ungkapan penjelasan diatas menunjukan selain hanya menutup sesi konseling kelompok saja tidak secara keseluruhan dikarenakan korban Narkotika, Psikotropika, dan Zat Adiktif (NAPZA) bisa kembali lagi memakai narkoba jika kebutuhan secara psikologinya tidak tertangani.

\section{Efektivitas Konseling Kelompok terhadap Motivasi Berhenti Memakai NAPZA}

Efektivitas Konseling Kelompok terhadap Motivasi Berhenti Memakai Narkotika, Psikotropika, dan Zat Adiktif (NAPZA) di Komunitas Pendidikan NAPZA Tasikmalaya (Pentas) di Ciputri, Kecamatan Singaparna, Kabupaten Tasikmalaya, Jawa Barat peneliti menggunakan angket yang dibuat dalam bentuk angket tertutup yang berjumlah 8 item pernyataan dengan menggunakan 5 alternatif jawaban yaitu sangat setuju, setuju, ragu-ragu, tidak setuju, dan sangat tidak setuju.

Data yang telah terkumpul dari hasil penyebaran angket kepada responden terlebih dahulu di uji tingkat validitas dan reliabilitas. Berikut ini adalah pengujian validitas dan reliabilitas Efektivitas Konseling Kelompok terhadap Motivasi Berhenti Memakai Narkotika, Psikotropika, dan Zat Adiktif (NAPZA) di Komunitas Pendidikan NAPZA Tasikmalaya (Pentas) di Ciputri, Kecamatan Singaparna, Kabupaten Tasikmalaya, Jawa Barat sebagai berikut : (A) Pengujian Instrument Penelitian Alat ukur yang digunakan sebagai alat pengukuran data salah satu bentuknya adalah angket. Dari hasil penyebaran angket tersebut, perlu dilakukan pengujian sebelum data-data tersebut dapat digunakan. Untuk memastikan hal tersebut, peneliti menggunakan data uji instrumen. Yaitu uji validitas dan uji realibilitas terhadap alat ukur berupa angket yang akan digunakan sebagai berikut: (a) Pengujian Validitas dapat menunjukan sejauh mana alat ukur penelitian mampu mengukur variabel yang terdapat pada suatu penelitian. Oleh karena itu, validitas merupakan suatu ukuran yang menunjukan tingkat kesetabilan, suatu alat ukur yang sahih akan mempunyai validitas yang tinggi, begitu pula sebaliknya alat ukur yang kurang valid mempunyai nilai rendah.

Untuk menguji validitas dapat diukur menggunakan rumus korelasi product moment pearson sebagai berikut:

$$
r_{x y}=\frac{n \sum x y-\left(\sum x\right)\left(\sum y\right)}{\sqrt{n}\left(\sum x^{2}\right)-\left(\sum X\right)^{2} n\left(\sum y^{2}\right)-\left(\sum y^{2}\right)}
$$

Keterangan : 
$\mathrm{r}_{x y} \quad$ : Koefisien korelasi

$\mathrm{N} \quad$ : Banyaknya sampel

$\sum \boldsymbol{X}$ : Jumlah skor keseluruhan untuk item pertanyaan variabel $\mathrm{X}$

$\sum \boldsymbol{Y}$ : Jumlah skor keseluruhan untuk responden ke- $n$

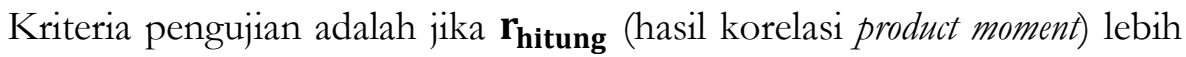
besar dari $\mathbf{r}_{\text {tabel }}$ Ho ditolak, maka item angket tersebut valid dan sebaliknya. Jika instrumen valid, maka dilihat kriteria penafsiran mengenai indeks korelasinya. Adapun $\mathrm{r}$ tabel apabila diketahui signifikasi $\alpha=0,05$ dan $\mathrm{df}=\mathrm{n}-2=29-2=27$ maka diperoleh $\mathrm{r}$ tabel $=0,381$.

Berdasarkan hasil perhitungan dengan menggunakan bantuan software SPSS versi 25, diketahi bahwa skor total dapat dilihat pada tabel IV.06 Sebagai berikut :

Tabel Iv.06

Item Total Efektivitas Konseling Kelompok Terhadap Motivasi

Berhenti Memakai Narkotika, Psikotropika, Dan Zat Adiktif (Napza)

\begin{tabular}{|l|r|r|r|r|}
\hline \multicolumn{5}{|c|}{ Item-Total Statistics } \\
\hline tem & $\begin{array}{r}\text { Mean if Item } \\
\text { Deleted }\end{array}$ & $\begin{array}{r}\text { Scale } \\
\text { Variance if } \\
\text { Item Deleted }\end{array}$ & $\begin{array}{r}\text { Correct } \\
\text { ed Item-Total } \\
\text { Correlation }\end{array}$ & $\begin{array}{c}\text { Cronbach's } \\
\text { Alpha if Item } \\
\text { Deleted }\end{array}$ \\
\hline tem 1 & 29,97 & 8,534 &, 521 &, 758 \\
\hline Item 2 & 29,83 & 8,719 &, 476 &, 764 \\
\hline Item 3 & 30,03 & 8,820 &, 436 &, 770 \\
\hline Item 4 & 30,62 & 8,030 &, 467 &, 768 \\
\hline Item 5 & 29,93 & 8,138 &, 655 &, 738 \\
\hline Item 6 & 29,93 & 8,424 &, 558 &, 752 \\
\hline Item 7 & 30,31 & 8,293 &, 461 &, 767 \\
\hline Item 8 & 30,52 & 8,044 &, 426 &, 777 \\
\hline
\end{tabular}

Sumber Hasil Pengolahan Data, pada 24 Juni 2019

Kemudian dari tabel IV.06 di atas dapat diketahui bahwa semua data valid untuk Efektivitas Konseling Kelompok Terhadap Motivasi Berhenti Memakai Narkotika, Psikotropika, dan Zat Adiktif (NAPZA) karena nilai r korelasinya lebih besar dari nilai $\mathrm{r}$ kritis $=0,381$ yang berarti bahwa setiap item pernyataan memiliki 
tingka validitas yang tinggi.

Pengujian Reliabilitas adalah tingkat kepercayaan dari suatu tingkat pengukuran. Pengukuran yang memiliki reliabilitas tinggi, yaitu pengukuran yang mampu memberikan hasil ukur yang terpercaya (reliabel). Tinggi rendahnya reliabilitas, secara empiris ditunjukan oleh suatu angka yang disebut koefisien reliabilitas.

Teknik perhitungan koefisien reliabilitas yang digunakan dalam penelitian ini adalah dengan menggunakan koefisien reliabilitias alpa cronbach yang dihitung dengan menggunakan rumus sebagai berikut :

$$
\mathrm{r}=\left[\frac{K}{K-1}\right]\left[\frac{1-\sum \mathrm{SI}}{\mathrm{SI}^{2}}\right]
$$

Keterangan :

$$
\begin{array}{ll}
\mathrm{r} & \text { : Reliablitias alat ukur } \\
\Sigma \text { SI } & \text { : Jumlah varian item } \\
\mathrm{K} & \text { : Banyaknya butir pertanyaan } \\
\mathrm{SI} & \text { : Varians total }
\end{array}
$$

Pada penelitian ini metode pengukuran reliabilitas alpha cronbach dibantu dengan software SPSS versi 25 . Kriteria yang harus dipenuhi oleh suatu alat ukur adalah 0,70. Hal ini berarti bahwa secara keseluruhan alat ukur yang digunakan telah memiliki konsistensi internal yang dapat diandalkan. Selanjutnya uji reliabilitas untuk Efektivitas Konseling Kelompok Terhadap Motivasi Berhenti Memakai Narkotika, Psikotropika, dan Zat Adiktif (NAPZA) dapat dilihat pada tabel IV.07 berikut:

$$
\text { Tabel Iv.07 }
$$

Data Hasil Pegujian Reliabilitas Efektivitas Konseling Kelompok Terhadap Motivasi Berhenti Memakai Narkotika, Psikotropika, Dan Zat Adiktif (Napza)

\begin{tabular}{|c|c|c|c|}
\hline \multicolumn{4}{|c|}{ Reliability Statistics } \\
\hline Cronbach's Alpha & N of Items & Titik Kritis & Keterangan \\
\hline 0,785 & 8 & 0,70 & $(0,785>070)$ Reliabel \\
\hline
\end{tabular}

Sumber Hasil Pengolahan Data, pada 24 Juni 2019

Dari tabel di atas tersebut menunjukan nilai alpha cornbach's lebih besar dari nilai titik kritis yaitu 0,70, maka hasil ini menunjukan bahwa instrumen angket yang dibuat reliabel dan memiliki reliabilitas tinggi. Oleh karena itu, maka instrumen angket memenuhi persyaratan untuk digunakan sebagai alat pengumpul data dalam penelitian ini.

\section{Faktor Pendukung Dan Penghambat Proses Konseling Kelompok Di Komunitas Pendidikan NAPZA}

Setiap pelaksanaan kegiatan yang mana di dalamnya melibatkan banyak 
orang tentu akan menghadapi berbagai faktor pendukung maupun hambatan. Dalam komunitas Pendidikan NAPZA Tasikmalaya (Pentas) di Ciputri, Kecamatan Singaparna, Kabupaten Tasikmalaya, Jawa Barat faktor pendukung yang menunjang kegiatan diantaranya sebagai berikut : (1) Anggota komunitas Pendidikan NAPZA Tasikmalaya (Pentas) di Ciputri, Kecamatan Singaparna, Kabupaten Tasikmalaya, Jawa Barat memiliki kemauan yang tinggi untuk pulih. (2) Konselor adalah eks pemakai Narkotika, Psikotropika, dan Zat Adiktif (NAPZA). Hal ini sebagai faktor pendukung karena konselor mengetahui kebutuhan serta keperluan anggota untuk menghadapi segala kemungkinan tantangan dan hambatan dalam proses pemulihan. (3) Konselor mengetahui proses konseling kelompok yang konsepnya yang sesuai dengan tujuan anggota komunitas Pendidikan NAPZA Tasikmalaya (Pentas) di Ciputri, Kecamatan Singaparna, Kabupaten Tasikmalaya, Jawa Barat.

Sedangkan faktor penghambat komunitas Pendidikan NAPZA Tasikmalaya (Pentas) di Ciputri, Kecamatan Singaparna, Kabupaten Tasikmalaya, Jawa Barat yang dihadapi diantaranya sebagai berikut : (a) Tidak adanya bantuan program dari pemerintah sejak tahun 2018, sehingga tidak ada yang memberikan program yang terarah dan jelas sesuai dengan standard pemerintah. (b) Masih kurang konselor yang menangani anggota komunitas. Apalagi konselor juga tidak hanya mengurus komunitas Pendidikan NAPZA Tasikmalaya (Pentas) di Ciputri, Kecamatan Singaparna, Kabupaten Tasikmalaya, Jawa Barat. Akan tetapi korban lainnya yang dalam wilayah cakupan Tasikmalaya. (c) Pasang surutnya untuk melakukan konseling kelompok karena terhambat oleh pekerjaan maupun urusan lainnya pada masing-masing anggota komunitas Pendidikan NAPZA Tasikmalaya (Pentas) di Ciputri, Kecamatan Singaparna, Kabupaten Tasikmalaya, Jawa Barat.

\section{PENUTUP}

Proses konseling kelompok di komunitas Pendidikan NAPZA Tasikmalaya (Pentas) di Ciputri, Kecamatan Singaparna, Kabupaten Tasikmalaya, Jawa Barat dapat berjalan dengan baik. Ditinjau sesuainya interaksi pada dinamika kelompok, sesuainya tahapan proses kelompok, dan juga adanya dorongandorongan terapeutik.

Konseling kelompok sangat efektif untuk meningkatkan motivasi anggota komunitas Pendidikan NAPZA Tasikmalaya (Pentas) di Ciputri, Kecamatan Singaparna, Kabupaten Tasikmalaya, Jawa Barat berhenti memakai Narkotika, Psikotropika, dan Zat Adiktif (NAPZA) dengan presentase 86,12\%.

Faktor pendukung di komunitas Pendidikan NAPZA Tasikmalaya (Pentas) di Ciputri, Kecamatan Singaparna, Kabupaten Tasikmalaya, Jawa Barat adalah sebagai berikut : (a) Anggota memiliki kemauan yang tinggi untuk pulih (b) Konselor adalah eks pengguna Narkotika, Psikotropika, dan Zat Adiktif 
(NAPZA). Hal ini sebagai faktor pendukung karena konselor mengetahui kebutuhan serta keperluan anggota untuk menghadapi segala kemungkinan tantangan dan hambatan dalam proses pemulihan. (c) Konselor mengetahui proses konseling kelompok yang konsepnya yang sesuai dengan tujuan anggota komunitas Pendidikan NAPZA Tasikmalaya (Pentas) di Ciputri, Kecamatan Singaparna, Kabupaten Tasikmalaya, Jawa Barat.

Sedangkan faktor penghambat komunitas Pendidikan NAPZA Tasikmalaya (Pentas) di Ciputri, Kecamatan Singaparna, Kabupaten Tasikmalaya, Jawa Barat yang dihadapi diantaranya sebagai berikut : (a) Tidak adanya bantuan program dari pemerintah sejak tahun 2018, sehingga tidak ada yang memberikan program yang terarah dan jelas sesuai dengan standard pemerintah. (b) Masih kurang konselor yang menangani anggota komunitas. (c) Pasang surutnya untuk melakukan konseling kelompok karena terhambat oleh pekerjaan maupun urusan lainnya pada masing-masig anggota komunitas

\section{DAFTAR PUSTAKA (Style Jurnal_2.1 Heading)}

Alwi, Hasan. 2007. Kamus Besar Babasa Indonesia. Jakarta: Balai Pustaka.

Arikunto, Suharsimi. 2010. Prosedur Penelitian Suatu Pendekatan Praktek. Jakarta: Bineka Cipta.

Arikunto, Suharsimi. 2013. Manajemen Penelitian. Jakarta: Rineka Cipta.

AS, Enjang dan Aliyudin. 2009. Dasar-dasar Ilmu Dakwah. Bandung: Widya Padjadjaran.

Bungin, Burhan. 2005. Metodologi Penelitian Kuantitatif. Jakarta: Kencana.

Djaali. 2009. Psikologi Pendidikan. Jakarta: Bumi Aksara.

Faqih, Aunur Rahim. 2001. Bimbingan dan Konseling dalam Islam. Yogyakarta: UII Press.

Folastri, Sisca dan Itsar Bolo Rangka. 2016. Prosedur Layanan Bimbingan \& Konseling Kelompok. Bandung: Mujahid Press.

Ghufron, M. Nur dan Rini Risnawati S. 2014. Teori-teori Psokologi. Jogjakarta: Ar Ruzz Media.

Hamalik, Oemar. 2001. Proses Belajar Mengajar. Jakarta: Bumi Aksara.

Jazuli, Ahmad. 2007. Upaya Menjaga Diri Dari Bahaya Narkoba. Semarang: Bengawan Ilmu.

Kurtanto, M. Edi. 2014. Konseling Kelompok. Bandung: Alfa Beta.

Makmun, Abin Syamsuddin. 2007. Psikologi Kependidikan. Bandung: Remaja Rosdakarya.

Affan, Heyder. 2018. Narkoba di Indonesia terus Meningkat. https://www.bbc.com/indonesia/indonesia-43198966. Diakses 01

Oktober 2018. Diakses pada pukul 20.10 WIB 
Arifianto, Bambang. Program Pemberantasan Narkoba di Tasikmalaya Sentuh Level Kelurahan. https://www.pikiran-rakyat.com/jawabarat/2019/03/19/progr am-pemberantasan-narkoba-di-tasikmalayasentuh-level-kelurahan. Diakses tanggal 03 Agustus 2019 pada pukul 11.48 WIB.

Badan Narkotika Nasional. 2016. Negara Pengedar Narkoba Terbesar di Dunia. http://lampung.bnn.go.id/wp/2016/12/05/7-negara-pengedarnarkoba-terbesar-di-dunia/. Diakses 01 Oktober 2018 pada pukul 10.20 WIB.

Badan Narkotika Nasional. 2017. Prevalensi Penyalahgunaan Narkoba di Indonesia dan Ancaman Bencana Demografi. http://diklat.bnn.go.id/?p=4400. Diakses 16 Februari 2019 pada pukul 13.09 WIB.

Dinilah, Mukhlis. 2017. Survei BNN 80 Persen Tahu Bahaya Narkoba, Kenapa Kasus Masih Tinggi?. https://news.detik.com/berita/d-3425965/surveibnn-80-persen-tahu-bahaya-narkoba-kenapa-kasus-masih-tinggi. Diakses 16 Februari 2019 pada pukul 12.03 WIB.

Heri Herdiansah, Isep. Penyalahgunaan Narkoba di Jabar Meningkat, Tasikmalaya Jadi Wilayah Transit Perdagangan. https://jabar.tribunnews.com/2019/07/26/pe nyalagunaan-narkoba-dijabar-meningkat-tasikmalaya-jadi-wilayah-transit-perdagangan-narkoba.

Diakses tanggal 03 Agustus 2019 pada pukul 11.38 WIB.

Lukihardianti, Arie. Jabar Jadi Pusat Rehabilitasi Narkotika. https://www. republika.co.id/berita/nasional/jawa-barat-nasional/14/04/07/n3nk y9 jabar-jadi-pusat-rehabilitasi-narkotika. Diakses tanggal 29 Juni 2019 pada pukul 15.00 WIB.

Pratiwi, Priska Sari. 2017. BNN: Jawa Barat, Pengguna Narkoba Terbanyak. https://www.beritasatu.com/kesra/226075-bnn-jawa-barat-penggunanarkoba-terbanyak.html. Diakses 03 Maret 2019 pada pukul 13.11 WIB.

Sari, Nursita. 2018. Indonesia Pasar Terbesar Pejualan dan Pengedaran Narkoba diAsia.https://megapolitan.kompas.com/read/2018/02/14/13273231/ bnn-indonesia-pasar-terbesar-penjualan-dan-peredaran-narkoba-di-asia. Diakses 01 Oktober 2018. 